\title{
The effect of cold-light-activated bleaching treatment on enamel surfaces in vitro
}

\begin{abstract}
Xin-Chang $\mathrm{Shi}^{1}, \mathrm{He} \mathrm{Ma}^{2}$, Jing-Lin $\mathrm{Zhou}^{1}$ and $\mathrm{Wei} \mathrm{Li}^{1}$
This in vitro study aims to evaluate the crystal and surface microstructure of dental enamel after cold-light bleaching treatment. Twelve sound human premolars were cross-split into four specimens, namely, mesio-buccal (Group LP), disto-buccal (Group P), mesio-lingual (Group NP) and disto-lingual (Group L) specimens. These four groups were treated using the standard cold-light bleaching procedure, a bleaching agent, a peroxide-free bleaching agent and cold-light, respectively. Before and after treatment, all specimens were analyzed by high-resolution, micro-area X-ray diffraction and scanning electron microscopy. Using a spectrometer, tooth color of all specimens was measured before and after treatment. The phase of the enamel crystals was identified as hydroxyapatite and carbonated hydroxyapatite. After treatment, specimens in Groups LP and P showed significantly weaker X-ray diffraction peaks, significant reduction in crystal size and crystallinity, significant increase in $L^{*}$ but decrease in $a^{*}$ and $b^{*}$, and obvious alterations in the surface morphology. However, specimens in Groups NP and L did not show any significant changes. The cold-light bleaching treatment leads to demineralization in the enamel surface. The acidic peroxide-containing bleaching agent was the major cause of demineralization, whereas cold-light did not exhibit significant increase or decrease effect on this demineralization.
\end{abstract}

International Journal of Oral Science (2012) 4, 208-213; doi:10.1038/ijos.2012.70; published online 21 December 2012

Keywords: dental enamel; light; micro-area X-ray diffraction; tooth bleaching

\section{INTRODUCTION}

Tooth bleaching, sometimes described as 'tooth whitening', is a popular treatment modality in dentistry. It offers a conservative and wellaccepted treatment option for discolored teeth compared with the resin-bonded composites, porcelain veneers or crowns. ${ }^{1}$ Current bleaching mechanisms are based on the application of hydrogen peroxide-releasing agents. Hydrogen peroxide may be applied directly, or it may be produced from carbamide peroxide. Carbamide peroxide, also called urea peroxide, is an adduct of hydrogen peroxide and urea. When dissolved in water or saliva, carbamide peroxide produces hydrogen peroxide and urea, which is further decomposed to carbon dioxide and ammonia. As the active agent of bleaching procedure, hydrogen peroxide penetrates the tooth, produces free radicals and interacts with chromophore molecules, oxidizing them. ${ }^{1-2}$ Many laboratory and clinical studies have demonstrated that bleaching agents containing hydrogen peroxide or carbamide peroxide are effective for bleaching discolored teeth. ${ }^{3-5}$ Carbamide peroxide can continuously produce hydrogen peroxide with less irritation, so it is generally used as home-bleaching agent. The common concentration of carbamide peroxide is $10 \%$.

Numerous previous studies have evaluated the adverse effects of peroxide-containing bleaching products on tooth enamel and/or dentin. However, these studies have conflicting results. Some studies have reported no significant deleterious effects on the surface micro-hardness, morphology, chemistry or ultrastructure of the enamel and/or dentine after bleaching treatment. ${ }^{6-11}$ On the contrary, other studies have indeed observed deleterious effects on the enamel and/or dentine, such as decrease in micro-hardness, ${ }^{12-16}$ alteration of surface morphology, ${ }^{15,17-18}$ changes in chemical composition and structure, ${ }^{19-21}$ loss of calcium and phosphorus, ${ }^{21-22}$ and decrease in the fracture resistance $^{23-24}$ and elastic modulus. ${ }^{16}$

The cold-light bleaching technique is a novel bleaching technique widely applied in mainland China. It is a light-activated, in-office bleaching technique using blue light (wavelength between $480 \mathrm{~nm}$ and $520 \mathrm{~nm}$ ). The cold-light lamp is equipped with filter to exclude the harmful infrared (wavelength $\lambda>750 \mathrm{~nm})$ and ultraviolet $(\lambda<$ $380 \mathrm{~nm}$ ). The exclusion of infrared reduces its thermal pulp damage. The ultraviolet is excluded to reduce the risk of possible side effects of ultraviolet radiation on living cells. This technique has proven effective in bleaching discolored teeth. ${ }^{25-26}$ However, the effect of the cold-light bleaching treatment on enamel has not yet been studied.

Using a novel method, our study examined the effects of the coldlight bleaching technique on enamel. This method is able to precisely analyze the changes in enamel crystals, which are essential components of the enamel. The purpose of this in vitro study was to evaluate the adverse effects of cold-light bleaching treatment on enamel crystals. We expected that the novel method would provide research community with additional information to eliminate the conflict on the adverse effects of tooth bleaching.

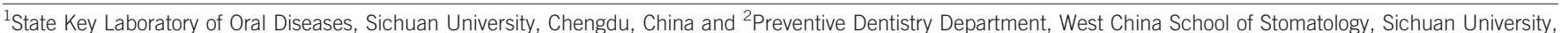
Chengdu, China

Correspondence: Dr W Li, State Key Laboratory of Oral Diseases, Sichuan University, Chengdu 610041, China

E-mail: leewei2000@sina.com

Received 17 February 2012; accepted 19 November 2012 


\section{MATERIALS AND METHODS}

\section{Tooth selection}

Twelve sound premolars, extracted for orthodontic reasons, were selected for this study. All twelve premolars had no apparent evidence of extrinsic staining, caries lesions, dental fluorosis, enamel hypoplasia, cracks or other defects on the buccal and lingual surfaces. The tooth surfaces were cleaned under high-pressure water for $10 \mathrm{~min}$ to remove the materia alba. Then, the teeth were stored in $0.1 \%$ thymol solution at $4{ }^{\circ} \mathrm{C}$ until the preparation for testing.

\section{Sample preparation}

The 12 teeth were randomly marked from 1 to 12 and washed in running deionized water for $24 \mathrm{~h}$ to completely remove thymol residue. Using a low speed, water-cooled saw (Isomet; Buehler Ltd, Lake Bluff, IL, USA), the root of each tooth was removed and the crown was cross-split bucco-lingually and mesio-distally into four specimens, namely, mesio-buccal, disto-buccal, mesio-lingual and disto-lingual specimens. As a result, four specimens were obtained from each tooth. The specimens from the first 10 teeth were collected for micro-area Xray diffraction (XRD) analysis and they were divided into the following four groups $(n=10)$ :

Group LP: mesio-buccal specimens, treated with cold-light combined with peroxide-containing bleaching agent; Group P: disto-buccal specimens, treated with peroxide-containing bleaching agent alone; Group NP: mesio-lingual specimens, treated with peroxide free bleaching agent; Group L: disto-lingual specimens, treated with coldlight alone.

The specimens from tooth number 11 and number 12 were collected for scanning electron microscopy (SEM) analysis. The mesiobuccal specimen of tooth number 11 was treated in the same manner as the Group LP specimens. The mesio-lingual specimen of tooth number 11 was treated in the same manner as the Group P specimens. The mesio-buccal specimen of tooth number 12 was treated in the same manner as the Group NP specimens. The mesio-lingual specimen of tooth number 12 was treated in the same manner as the Group L specimens. The disto-buccal and disto-lingual specimens of tooth number 11 and number 12 were stored in deionized water at $4{ }^{\circ} \mathrm{C}$ without any treatment.

The specimens were embedded in denture base resin with either the buccal or the lingual enamel surface exposed. The samples were then stored in deionized water at $4{ }^{\circ} \mathrm{C}$ until the next treatment.

\section{Bleaching procedure}

All specimens were washed under running deionized water for $30 \mathrm{~s}$ and dried with compressed air for $5 \mathrm{~s}$ before the bleaching treatment. Different bleaching agents were prepared for the different groups. Agent for Group LP and Group P was prepared by mixing the 35\% hydrogen peroxide solution and silicon dioxide catalyst (BEYOND II; Beyond Technology Ltd, Centennial, CO, USA), while agent for Group NP was prepared by mixing deionized water with the same silicon dioxide catalyst. The $\mathrm{pH}$ of the $35 \%$ hydrogen peroxide solution and the bleaching agents was measured three times using a $\mathrm{pH}$ meter (PT-10; Sartorius Ltd, Göttingen, Germany). The averages of $\mathrm{pH}$ value of $35 \%$ hydrogen peroxide solution, agents for Groups LP, P and NP were 6.0, 5.0, 5.0 and 5.9, respectively. The specimens of Group LP were treated according to the standard bleaching procedures, as follows: (i) the specimens surfaces were painted with whitening agent to form a uniform 2-3 mm thick layer; (ii) the head of cold-light lamp (BY-0398; Beyond Technology Ltd) was placed vertically $1 \mathrm{~cm}$ above the tooth surfaces and the lamp was switched on for $8 \mathrm{~min}$; (iii) the whitening agent was removed, and then steps (i)-(iii) were repeated twice; and finally (iv) the bleaching agent was removed and the tooth surfaces were cleaned with flowing deionized water for 1 min. The specimens of Group P and Group NP were treated with the same procedures as Group LP without the use of cold-light. The specimens of Group L were exposed under cold-light, as described for the specimens of Group LP in step (ii), for $24 \mathrm{~min}$. After bleaching treatment, all specimens were stored in deionized water at $4{ }^{\circ} \mathrm{C}$.

\section{Color measurement}

The colors of the specimens from the first 10 teeth were measured using a spectrometer (USB 2000; Ocean Optics, Dunedin, FL, USA). Before color measurement, all specimens were wetted with deionized water and then dried under compressed air for $5 \mathrm{~s}$ to ensure that no apparent water exists on the surface of specimens. Subsequently, the specimens were placed on dark paper. The illumination source in this study was a $3600 \mathrm{mcd}\left(I_{\mathrm{V}}\right)$ at $20 \mathrm{~mA}\left(I_{\mathrm{F}}\right)$ high-power white LED (NSPW300BS; Nichia, Tokushima, Japan). The light sensor was placed vertically above the specimens surfaces, and the illumination source was arranged at the position to ensure that the angle between incident ray and vertical axis or horizontal plane was $45^{\circ}$. The color of each specimen was measured three times to obtain a mean value. Prior to the bleaching treatment, the color of each specimen was measured to yield pre-treatment data. After the bleaching experiment, the color was measured again to yield post-treatment data. The color was recorded as $L^{*} a^{*} b^{*}$ Commission International de l'Eclairage (International Commission on Illumination) CIELAB coordinates. The values of $L^{*}, a^{*}$ and $b^{*}$ were recorded, and the changes before and after the experiment, between these values were expressed as $\Delta L^{*}$, $\Delta a^{*}$ and $\Delta b^{*}$, respectively.

\section{High-resolution, micro-area XRD analysis}

To evaluate the changes in the crystal phase and size of enamel after cold-light bleaching, specimens were analyzed before and after the bleaching procedure using a high-resolution, micro-area XRD (X'Pert PRO; PANalytical Ltd, Almelo, The Netherlands). The scanning range was from $20^{\circ}$ to $60^{\circ}$, with a scanning speed of $0.2122^{\circ}$ per minute and a step size of $0.0334^{\circ}$ per minute. The radiation utilized was CuK-Alpha1 $(\lambda=0.15406 \mathrm{~nm})$. The depth of X-ray penetration was less than $10 \mu \mathrm{m}$, and the area of light spot was $100 \mu \mathrm{m}^{2}$. Micro-area XRD data were analyzed using MDI Jade 5.0 and Philips X'Pert HighScore 1.0 to evaluate the enamel crystal phase, crystal size and crystallinity. The enamel crystal size and crystallinity were calculated with MDI Jade 5.0. The 'Peak Paint' function of MDI Jade 5.0 was used to calculate the peak area and the software would then automatically report the crystal size. The crystallinity was calculated according to the formula below: Crystallinity $=($ Diffraction Peaks Intensity/Total Intensity) $\times 100 \%$. The 'Profile Fitting' function of MDI Jade 5.0 was used to fit the peaks one by one and the software would then automatically report the crystallinity. Crystal size and crystallinity data were analyzed using SPSS 10.0 for Windows, and the Student's $t$-test and analysis of variance (ANOVA) were used to test the statistical significance of the data $(P<0.05)$.

\section{SEM analysis}

SEM (Inspect F; FEI Ltd, Eindhoven, The Netherlands), with a resolution power of $1.3 \mathrm{~nm}$, was applied to observe the morphological changes in the enamel surface before and after the bleaching treatment. The micrographs are reproduced in Figure 1. 

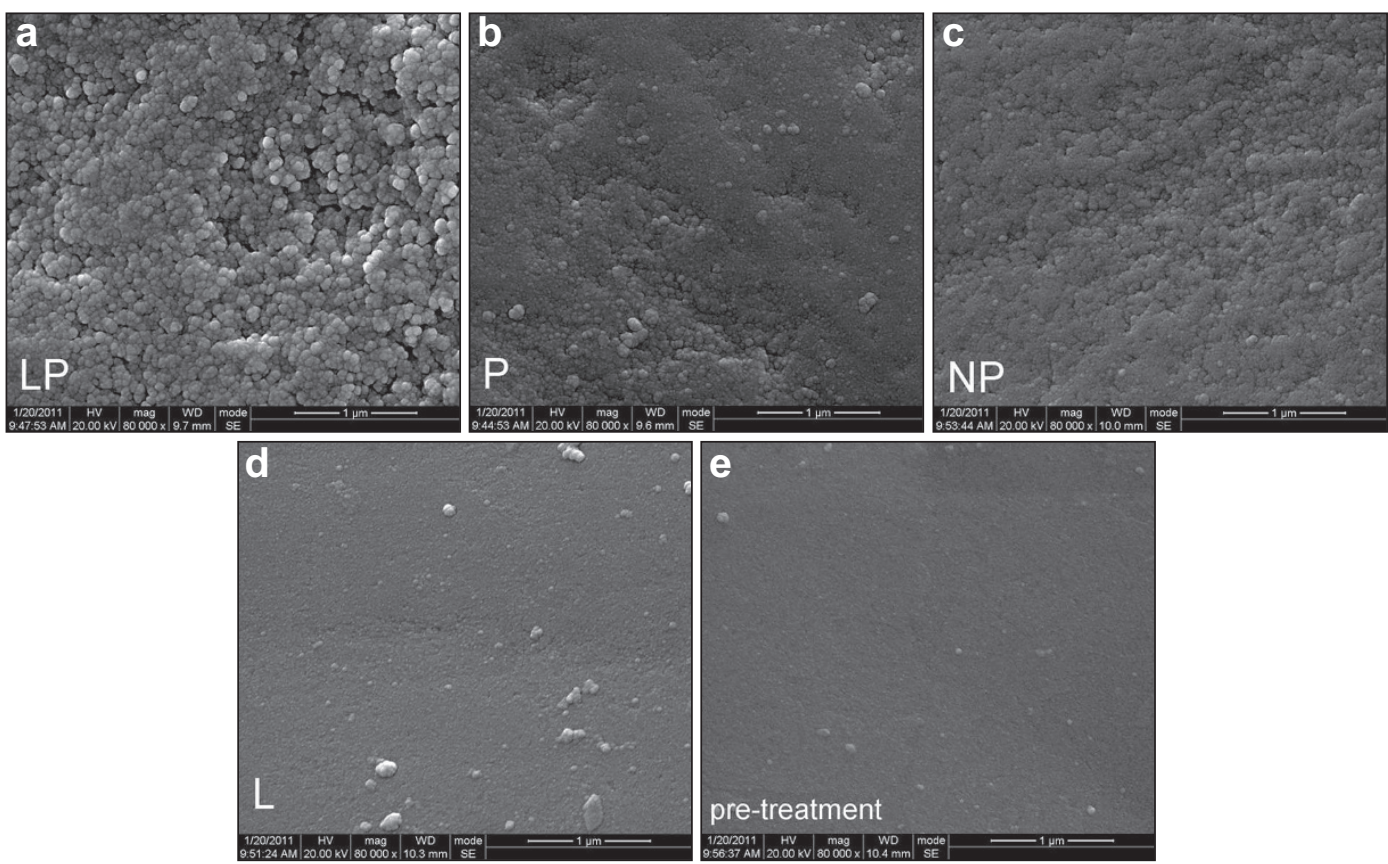

Figure 1 SEM micrograph of specimen. (a) Post-treatment specimen of Group LP, $\times 80000$ original magnification; (b) post-treatment specimen of Group P, $\times 80000$ original magnification; (c) post-treatment specimen of Group NP, $\times 80000$ original magnification; (d) post-treatment specimen of Group L, $\times 80000$ original magnification; (e) pre-treatment specimen, $\times 80000$ original magnification. SEM, scanning electron microscopy.

\section{RESULTS}

\section{Color measurement}

The mean values and standard deviation (s.d.) of $\Delta L^{*}, \Delta a^{*}$ and $\Delta b^{*}$ are shown in Table 1. As shown in Table 1, in Groups LP and P, significant changes in tooth color occurred after treatment. A statistically significant increase was observed in $L^{*}$, whereas a decrease was observed in both $a^{*}$ and $b^{*}$. However, in Groups NP and Group L, no statistically significant tooth color changes were observed. These changes verified that tooth whitening occurred in Groups LP and P.

\section{Enamel crystal phase}

The XRD patterns of specimens from the four groups are shown in Figure 2 (Figure 2a for Group LP; Figure 2b for Group P; Figure 2c for Group NP; and Figure 2d for Group L). The pre-treatment and posttreatment patterns are displayed in one figure for comparison. As the XRD patterns shows, the major phases of the specimens are hydroxyapatite (HA) and carbonated hydroxyapatite (CHA). Comparing the pre-treatment pattern with that of the post-treatment in Groups LP and P, the pre-treatment peaks were sharper than the post-treatment peaks. Meanwhile, some peaks clearly visible in the pre-treatment pattern became weak or even disappeared at the same site in the

Table 1 Mean (s.d.) of $\Delta L^{*}, \Delta a^{*}$ and $\Delta b^{*}$ in specimens of Group LP, Group P, Group NP and Group L

\begin{tabular}{lccc}
\hline Groups & $\Delta L^{*}$ & $\Delta a^{*}$ & $\Delta b^{*}$ \\
\hline LP & $3.8(2.8)^{\mathrm{a}}$ & $-0.6(0.3)^{\mathrm{a}}$ & $-2.9(2.0)^{\mathrm{a}}$ \\
P & $3.2(2.9)^{\mathrm{a}}$ & $-0.6(0.4)^{\mathrm{a}}$ & $-2.7(2.3)^{\mathrm{a}}$ \\
NP & $0.9(1.4)^{\mathrm{b}}$ & $-0.3(0.5)^{\mathrm{b}}$ & $-0.6(1.1)^{\mathrm{b}}$ \\
$\mathrm{L}$ & $0.5(0.9)^{\mathrm{b}}$ & $-0.4(0.6)^{\mathrm{b}}$ & $-0.4(0.7)^{\mathrm{b}}$ \\
\hline
\end{tabular}

${ }^{a}$ Student's $t$-test indicated statistically significant difference in pre-treatment $v s$. post-treatment measure $(P<0.05)$.

${ }^{\mathrm{b}}$ Student's $t$-test indicated no statistically significant difference in pre-treatment $v s$. post-treatment measure $(P>0.05)$. post-treatment pattern. However, in Groups NP and L, the changes in peaks were not significant.

\section{Enamel crystal size and crystallinity}

The crystal size and crystallinity of the specimens were calculated from the XRD data for three times and the changes of each after different treatment are shown in Table 2. Generally, the values of crystal size and crystallinity decreased after treatment in Group LP, Group P and Group NP. The changes were most distinct in Group LP. The means (and s.d.) of the changes in the crystal size and crystallinity of Group LP were -2.78 (2.35) $\mathrm{nm}$ and $-2.548 \%$ $(0.02173 \%)$, respectively. The results of the Student's $t$-test showed significant decrease in crystal size and crystallinity after treatments in Group LP $(P<0.005)$ and Group $\mathrm{P}(P<0.01)$. However, the changes in Group NP and Group L had no statistically significance $(P>0.05)$. The results of the ANOVA indicated a statistically significant difference in the changes of crystal size and crystallinity in Group LP vs. Group NP, Group LP vs. Group L, Group P vs. Group NP and Group P vs. Group L, respectively $(P<0.01)$. However, the ANOVA indicated no statistically significant difference in Group LP vs. Group P, as well as Group NP vs. Group L $(P>0.05)$. It is known that crystals with higher crystallinity have sharper diffraction peaks and, conversely, low crystallinity results in weak or even no diffraction peaks. ${ }^{27}$ Thus, the results of crystallinity were consistent with the XRD patterns shown in Figure 2.

\section{Enamel surface morphology}

The high-resolution SEM micrographs of specimens are shown in Figure 1 (Figure 1a for post-treatment specimens of Group LP; Figure 1b for post-treatment specimens of Group P; Figure 1c for post-treatment specimens of Group NP; Figure 1d for post-treatment specimens of Group L; and Figure 1e for pre-treatment specimens). As Figure 1 shows, the surface morphology of pre-treatment specimens was 

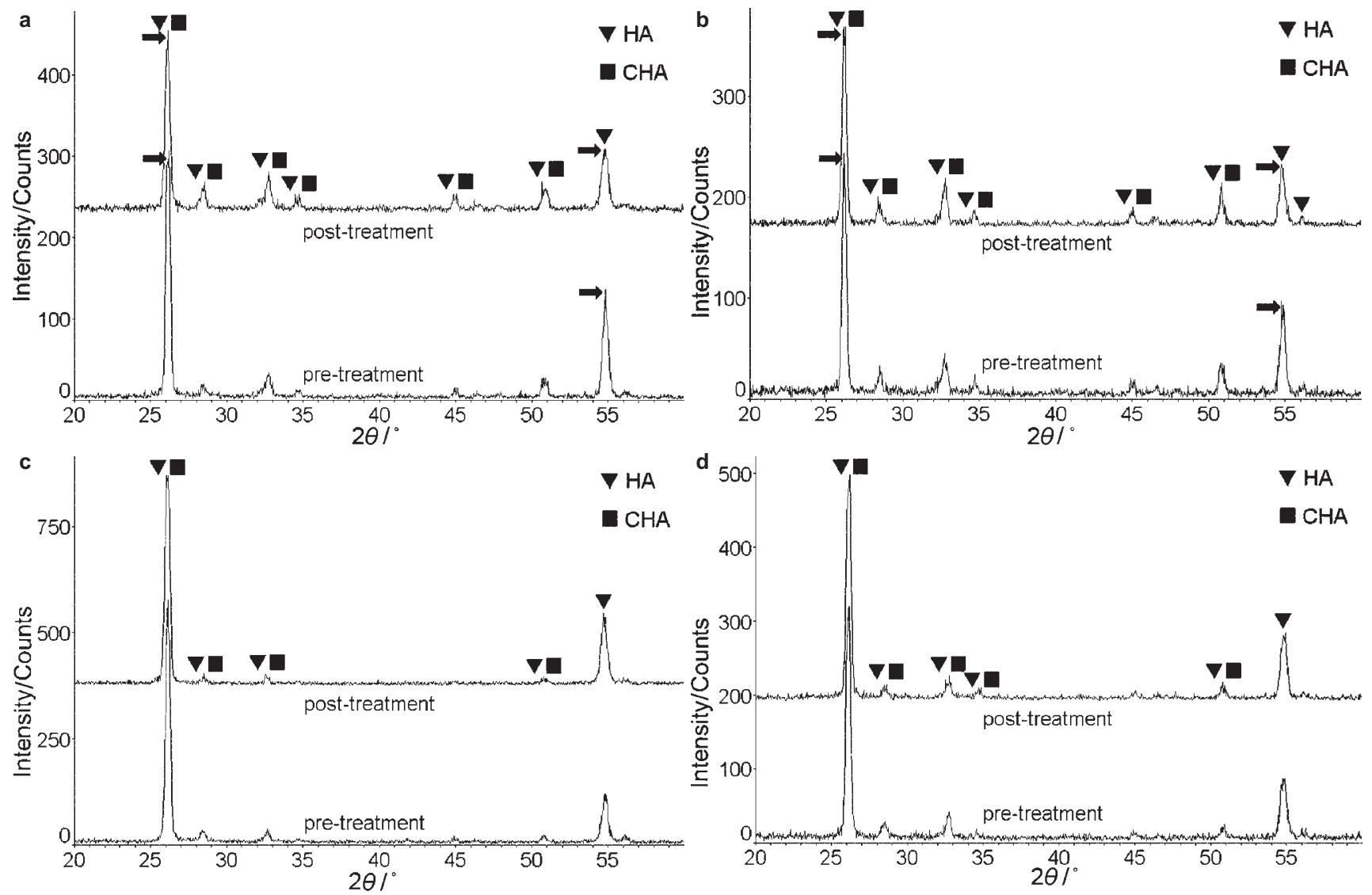

Figure 2 Pre-treatment and post-treatment XRD patterns of specimen. (a) Group LP. 'HA' and 'CHA' refer to 'hydroxyapatite' and 'carbonated hydroxyapatite', respectively. Arrows indicated the obvious difference between the pre-treatment and post-treatment XRD patterns. (b) Group P. 'HA' and 'CHA' refer to 'hydroxyapatite' and 'carbonated hydroxyapatite', respectively. Arrows indicated the obvious difference between the pre-treatment and post-treatment XRD patterns. (c) Group NP. 'HA' and 'CHA' refer to 'hydroxyapatite' and 'carbonated hydroxyapatite', respectively. (d) Group L. 'HA' and 'CHA' refer to 'hydroxyapatite' and 'carbonated hydroxyapatite', respectively. XRD, X-ray diffraction.

similar to that of post-treatment specimens of Group L, which appeared as a smooth flat surface. However, the surface morphology of post-treatment specimens of Group LP, Group P and Group NP was no longer smooth. Instead, a rough surface was observed, and a

Table 2 Mean (s.d.) of crystal size and crystallinity changes after treatment in specimens of Group LP, Group P, Group NP and Group L

\begin{tabular}{lclc}
\hline Groups & Changes in crystal size/nm & Changes in crystallinity/\% & Agent pH \\
\hline LP & $-2.78(2.35)^{* *, a, b, c}$ & $-2.548(0.02173)^{* *, a, b, c}$ & 5.0 \\
P & $-2.23(2.05)^{*, d, e}$ & $-2.105(0.01914)^{*, d, e}$ & 5.0 \\
NP & $-0.86(1.21)^{f, g}$ & $-0.647(0.00912)^{\mathrm{f}, \mathrm{g}}$ & 5.9 \\
$\mathrm{~L}$ & $-0.10(0.15)^{\mathrm{f}}$ & $-0.013(0.00022)^{\mathrm{f}}$ & - \\
\hline
\end{tabular}

$* *, *$ Student's $t$-test indicated a statistically significant decrease in post-treatment vs. pre-treatment measure $(* * P<0.005, * P<0.01)$.

${ }^{f}$ Student's $t$-test indicated no statistically significant difference in pre-treatment $v s$. post-treatment measure $(P>0.05)$.

$\mathrm{b}, \mathrm{c}, \mathrm{d}, \mathrm{e}$ ANOVA indicated a statistically significant difference in Group LP vs. Group NP, Group LP vs. Group L, Group P vs. Group NP and Group P vs. Group L, respectively $(P<0.01)$.

${ }^{a, g}$ ANOVA indicated no statistically significant difference in Group LP vs. Group P and Group NP vs. Group L, respectively ( $P>0.05)$. clear spherical enamel crystal structure can be identified. These changes were most evident in Group LP among the four groups.

\section{DISCUSSION}

The significant work in our study was the application of microarea XRD to evaluate the changes after tooth bleaching. This approach has never before been applied in evaluating the effects of a bleaching procedure on enamel. As is widely known, dental enamel is the hardest and most highly mineralized biological tissue. It is composed of approximately $96 \%$ minerals, $3 \%$ water and $1 \%$ organic matter by weight. ${ }^{28-29}$ The $96 \%$ mineral component, always referred to as enamel crystal, is the primary constituent of dental enamel. Micro-area XRD is a common approach used in materials science to analyze crystals, so it also can be applied in analyzing dental enamel. It enables the enamel crystal to be investigated in a non-destructive way. Furthermore, no special pretreatment of specimens is necessary prior to micro-area XRD analysis, unlike others, more common methods, such as microhardness measurements. In micro-hardness measurements, it is necessary to flatten the upper surface layer of enamel to provide a more uniform surface, thereby improving the precision of the indentations. ${ }^{12-16}$ This procedure will lead to unreliable results in evaluating the adverse effects of peroxide-containing bleaching products on dental enamel, ${ }^{9}$ because the removed upper surface 
layer, the chief structure of which is prismless enamel, is generally more highly mineralized than the subsurface and is thus more resistant to demineralization. ${ }^{30}$ In the present study, the depth of $\mathrm{X}$-ray penetration was less than $10 \mu \mathrm{m}$. At this depth, the enamel is prismless enamel because the average thickness of prismless is approximately $30 \mu \mathrm{m} .{ }^{30}$ In our study, to keep the enamel intact and improve the reliability of the results, no polishing or flattening measures were applied on the enamel surface before the bleaching treatment.

The primary mineral in tooth enamel is HA. ${ }^{31}$ The XRD pattern of the specimens in the current study was identified as HA and CHA, which is in agreement with the results of a previous study. ${ }^{32}$ However, the observed peaks did not agree with the diffraction patterns of standard, artificially synthesized HA or CHA. In the XRD pattern of the specimens, some peaks were lower or weaker and some peaks had disappeared altogether compared with the standard HA or CHA diffraction patterns. This phenomenon could be explained by the low crystallinity of natural enamel crystals and the immaturity of the enamel specimens applied in the present study. The enamel specimens were obtained from 10 premolars, which were extracted for orthodontic reasons from young people aged $12-15$ years. It is known that after eruption, the tooth enamel will continue the mineralization in saliva before it reaches maturity.

The results from XRD patterns, enamel crystal size and crystallinity, as well as enamel surface SEM morphology, verified that changes occurred in enamel surface after cold-light tooth bleaching. These observed changes actually involved demineralization. There were three factors which may have influenced the enamel surface after bleaching, namely cold-light, peroxide in the bleaching agent and components of the bleaching agent other than peroxide. The cold-light, by itself, cannot cause demineralization. Thus, either peroxide or other components of the bleaching agent would be the causes of demineralization. The results in our study verified that $35 \%$ hydrogen peroxide solution had a major demineralization effect on enamel surface and the cold-light had no significant increase or decrease effect on this demineralization. The $35 \%$ hydrogen peroxide solution is acidic $(\mathrm{pH}=6.0)$, and its $\mathrm{pH}$ decreased further $(\mathrm{pH}=5.0)$ when the bleaching agents were prepared by mixing the $35 \%$ hydrogen peroxide solution with silicon dioxide catalyst. The critical $\mathrm{pH}$ for the occurrence of enamel demineralization is between 5.2 and $5.8 .^{33}$ Obviously, the $\mathrm{pH}$ of mixed bleaching agent was lower than 5.2, and it can easily initiate the dissolution of enamel crystals. As the $\mathrm{pH}$ value of whitening agent fell, hydrogen ions started to attack the enamel crystals, freeing calcium and phosphate ions from enamel surface. Additionally, the substitution of carbonate ions in the HA crystal lattice would cause disturbances in the regular array of ions in the crystal lattice, making the crystal susceptible to attack by hydrogen ions. ${ }^{34}$ Because the $96 \%$ component of enamel is inorganic mineral, the acid $\mathrm{pH}$ takes the primary demineralization effects on the enamel. The oxidative effects are more likely to occur deeper in the tooth, where more organic materials are present. ${ }^{17}$

\section{CONCLUSION}

We can conclude from this study that the cold-light bleaching treatment resulted in enamel surface demineralization in vitro. It reduced crystal size and crystallinity and led to obvious changes in the surface morphology of enamel surface. The acidic peroxide-containing bleaching agent was the major factor that caused enamel demineralization, whereas cold-light alone had no significant increase or decrease effect on this demineralization.

\section{ACKNOWLEDGEMENTS}

The authors thank Mr Chao-liang Zhang (State Key Laboratory of Oral Diseases, Sichuan University) for his assistance in the SEM analysis and Ms Ru Shen (Key Laboratory of Advanced Technologies of Materials, Ministry of Education, Southwest Jiaotong University) for her help with the micro-area XRD experiment.

1 Joiner A. The bleaching of teeth: a review of the literature. J Dent 2006; 34(7): 412419.

2 Dahl JE, Pallesen U. Tooth bleaching - a critical review of the biological aspects. Crit Rev Oral Biol Med 2003; 14(4): 292-304.

3 Deliperi S, Bardwell DN. Two-year clinical evaluation of non-vital tooth whitening and resin composite restorations. J Esthet Restor Dent 2005; 17(6): 369-378.

4 Hannig C, Lindner D, Attin T. Efficacy and tolerability of two home bleaching systems having different peroxide delivery. Clin Oral Invest 2007; 11(4): 321-329.

5 Wiegand A, Drebenstedt S, Roos M et al. 12-month color stability of enamel, dentine, and enamel-dentine samples after bleaching. Clin Oral Invest 2008; 12(4): 303310.

6 Joiner A, Thakker G, Cooper Y. Evaluation of a $6 \%$ hydrogen peroxide tooth whitening gel on enamel and dentine microhardness in vitro. J Dent 2004; 32(Suppl): 27-34.

7 Justino LM, Tames DR, Demarco FF. In situ and in vitro effects of bleaching with carbamide peroxide on human enamel. Oper Dent 2004; 29(2): 219-225.

8 Götz H, Duschner H, White DJ et al. Effects of elevated hydrogen peroxide 'strip' bleaching on surface and subsurface enamel including subsurface histomorphology, micro-chemical composition and fluorescence changes. J Dent 2007; 35(6): 457466.

9 Joiner A. Review of the effects of peroxide on enamel and dentine properties. J Dent 2007; 35(12): 889-896.

10 Cadenaro M, Breschi L, Nucci C et al. Effect of two in-office whitening agents on the enamel surface in vivo: a morphological and non-contact profilometric study. Oper Dent 2008; 33(2): 127-134.

11 Maia E, Baratieri LN, Caldeira de Andrada MA et al. The influence of two home-applied bleaching agents on enamel microhardness: an in situ study. J Dent 2008; 36(1): 27.

12 Lewinstein I, Fuhrer N, Churaru $\mathrm{N}$ et al. Effect of different peroxide bleaching regimens and subsequent fluoridation on the hardness of human enamel and dentin. J Prosthet Dent 2004; 92(4): 337-342.

13 Rodrigues JA, March GM, Ambrosano GM et al. Microhardness evaluation of in situ vital bleaching on human dental enamel using a novel study design. Dent Mater 2005; 21(11): 1059-1067.

14 Chen HP, Chang $\mathrm{CH}$, Liu JK et al. Effect of fluoride containing bleaching agents on enamel surface properties. J Dent 2008; 36(9): 718-725.

15 Jiang T, Ma X, Wang ZJ et al. Beneficial effects of hydroxyapatite on enamel subjected to 30\% hydrogen peroxide. J Dent 2008; 36(11): 907-914.

16 Azer SS, Machado C, Sanchez E et al. Effect of home bleaching systems on enamel nanohardness and elastic modulus. J Dent 2009; 37(3): 185-190.

17 Hegedüs $C$, Bistey T, Flóra-Nagy $E$ et al. An atomic force microscopy study on the effect of bleaching agents on enamel surface. J Dent 1999; 27(7): 509-515.

18 Spalding M, Taveira LA, Assis GF. Scanning electron microscopy study of dental enamel surface exposed to $35 \%$ hydrogen peroxide: alone, with saliva, and with 10\% carbamide peroxide. J Esthet Restor Dent 2003; 15(3): 154-165.

19 Al-Salehi SK, Wood DJ, Hatton PV. The effect of $24 \mathrm{~h}$ nonstop hydrogen peroxide concentration on bovine enamel and dentine mineral content and microhardness. J Dent 2007; 35(11): 845-850.

20 Bistey T, Nagy IP, Sim A et al. In vitro FT-IR study of the effects of hydrogen peroxide on superficial tooth enamel. J Dent 2007; 35(4): 325-330.

21 Severcan F, Gokduman K, Dogan A et al. Effects of in-office and at-home bleaching on human enamel and dentin: an in vitro application of Fourier transform infrared study. App/ Spectrosc 2008; 62(11): 1274-1279.

22 Tezel H, Ertas OS, Ozata F et al. Effect of bleaching agents on calcium loss from the enamel surface. Quintessence Int 2007; 38(4): 339-347.

23 Cavalli V, Giannini M, Carvalho RM. Effect of carbamide peroxide bleaching agents on tensile strength of human enamel. Dent Mater 2004; 20(8): 733-739.

24 Pobbe POS, Viapiana R, Souza-Gabriel AE et al. Coronal resistance to fracture of endodontically treated teeth submitted to light-activated bleaching. J Dent 2008; 36(11): 935-939.

25 Wang B, Liang JP. [Observation of the bleaching effect of Beyond whitening accelerator.] Chin J Conserv Dent 2006; 16(6): 337-339. Chinese.

26 Zhang Y, Kang YY, Sun Y. [The effect of Beyond cold light whitening kit on bleaching pulpless teeth.] Chin J Conserv Dent 2008; 18(11): 615-617. Chinese.

27 Huang JW. [Manual of MDI Jade.] Available at http://wenku.baidu.com/view/ 857703778e9951e79b892700.html (accessed 10 February 2012). Chinese. 
28 Deakins M, Volker JF. Amount of organic matter in enamel from several types of human teeth. J Dent Res 1941; 20(2): 117-121.

29 Cuy JL, Mann AB, Livi KJ et al. Nanoindentation mapping of the mechanical properties of human molar tooth enamel. Arch Oral Biol 2002; 47(4): 281-291.

30 Whittaker DK. Structural variations in the surface zone of human tooth ename observed by scanning electron microscopy. Archs Oral Biol 1982; 27(5): 383-392.

31 White T, Ferraris C, Kim J et al. Apatite: an adaptive framework structure. Rev Mineral Geochem 2005; 57(1): 307-401.

32 Sydney-Zax M, Mayer I, Deutsch D. Carbonate content in developing human and bovine enamel. J Dent Res 1991; 70(5): 913-916.

33 Driessens FC, Theuns HM, Borggreven JM et al. Solubility behavior of whole human enamel. Caries Res 1986; 20(2): 103-110.
34 Featherstone JDB. The science and practice of caries prevention. J Am Dent Assoc 2000; 131(7): 887-899.

This work is licensed under a Creative Commons

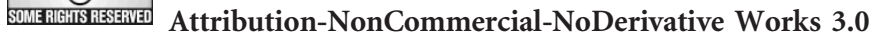
Unported License. To view a copy of this license, visit http:// creativecommons.org/licenses/by-nc-nd/3.0 